\title{
Investigating the contribution of the European Union Erasmus+ youth exchange project to foreign language learning ${ }^{*}+$
}

\author{
Koray Cantez a (D), Cihat Atar ${ }^{\circ}$ (1) \\ ${ }^{a}$ Sakarya University, Hendek, Sakarya 54000, Turkey
}

Received 13 October $2020 \quad$ ～Received in revised form 25 November $2020 \quad$ Accepted 09 March 2021

\begin{abstract}
APA Citation:
Cantez, K. \& Atar, C. (2021). Investigating the contribution of the European Union Erasmus+ youth exchange project to foreign language learning. Eurasian Journal of Applied Linguistics, 7(1), 259-276.
\end{abstract}

Doi: 10.32601/ejal.911281

\begin{abstract}
The purpose of this study is to investigate the views of the participants of European Union Erasmus+ Youth Exchange project regarding its effect on foreign language motivation and speaking fluency development. Foreign language motivation and speaking are two significant aspects of learning English as a foreign language. There are some studies on the effects of Erasmus+ projects; however, there are very few studies on the effect of Erasmus+ Youth Exchange projects in the literature. Having a qualitative design, this study utilizes purposive sampling method, and participants are those who attended the Erasmus+ Youth Exchange projects implemented between 2014 and 2020. The data were collected via a standardized open-ended interview. The interviews were transcribed and qualitatively analyzed by Content Analysis method via MAXQDA 2018 Qualitative Data Analysis Software. The findings of the research revealed that according to the views of the participants, EU Erasmus+ Youth Exchange Project provided several benefits to participants in terms of improving foreign language level, and the project contributed to their English-speaking fluency and foreign language learning motivation. More specifically, points such as opportunities to do practice, negative comments on Turkish Education System, educational equality provided by Erasmus + projects and follow-up activities carried out after projects were mentioned by the participants. These findings have implications for learning and teaching English as a foreign language.
\end{abstract}

(C) 2021 EJAL \& the Authors. Published by Eurasian Journal of Applied Linguistics (EJAL). This is an open-access article distributed under the terms and conditions of the Creative Commons Attribution license (CC BY-NC-ND) (http://creativecommons.org/licenses/by-nc-nd/4.0/).

Keywords: Erasmus+ Youth Exchange Project; speaking skills; motivation; out-of-class activities; nonformal education; foreign language learning

\section{Introduction}

\footnotetext{
" This study is based on the master's thesis titled "xxx" that is submitted to Sakarya University by xxx.

† This study has ethical approval from Sakarya University under the protocol number 61923333/050.99/ on 06/05/2020.

Corresponding author.

E-mail address: cihat.atar@sakarya.edu.tr

$\underline{\text { http://dx.doi.org/10.32601/ejal.911281 }}$
} 


\subsection{The problem}

Due to globalization, learning English has been a widespread phenomenon. According to many studies (Coşkun, 2016; Demirel, 1999; Haznedar, 2010; Işık, 2008; Kırkgöz, 2008; Koşar \& Bedir, 2014; Yurtsever Bodur \& Arıkan, 2017), foreign language teaching in Turkey has not been as successful as expected. Even though various methodologies have been introduced to the Turkish Educational Curriculum, significant success has never been attained as the studies suggested. One of the underlying reasons for the failure in foreign language learning is lack of practice and interaction in the target language. Learning a foreign language is an interactive and social process (Sabitha, 2013) and learners in countries in which English does not have a status (i.e. foreign language) cannot have the opportunity to practice and have social interaction sufficiently.

On the other hand, European Union (EU) Erasmus+ Projects provide great opportunities for individuals to take part in projects, make new friends, socialize, improve their foreign language proficiency, enjoy different cultures and gain new opportunities. Non-Governmental Organizations (NGOs) are institutions that include the life-long learning process, which means that the theoretical information not taught within the formal education frame can be socially acquired and experienced. Without the formal pressure and the artificial environment in schools, the participants have real-life experience in which they actively use English to undertake social activities and roles. As mentioned above, learners do not have enough opportunities to use and practice English. Hence, the EU Youth Exchange (YE) projects can help them overcome lack of motivation and it also has the potential to improve their speaking skills.

Accordingly, the purpose of the current study is to provide insights into Erasmus+ YE project in terms of its perceived effect on the participants' English speaking skills and their English Language learning motivation via interviews. An open-ended structured interview was applied to find out motivational contribution and improvement of speaking skills by EU YE according to the views of the participants.

\subsection{The significance of the study}

Erasmus+ projects have drawn the attention of many researchers that focused on their impact on foreign language learning. The studies carried out within Erasmus+ frame mainly focus on Erasmus+ Student Exchanges carried out by higher education institutions. Gürlek (2016) and Mulcar (2019) studied the effects of Erasmus+ Student Exchange Program on attitudes towards learning English. The results of the research suggested that the program helped participants either develop or improve positive attitudes towards learning English. Fombona et al. (2013) investigated the motivational factors of Erasmus students and found that the exchange program had a positive impact on foreign language learning. Similarly, Kayaoğlu (2016) studied the Erasmus Exchange Program to analyze students' perception and experiences and 
found that a vast majority of the students confirmed that they improved their foreign language skills. Özdemir (2019) studied the effects of studying in an ELF context on Turkish Erasmus Exchange students and their foreign language proficiency development. The results indicated that the program significantly contributed to students' foreign language skills.

As seen above, there are some studies in the literature; however, the present study differs from them in three significant aspects. First of all, the student exchanges carried out by higher education institutions take place in universities and students are expected to attend formal class education in accordance with the European Credit Transfer and Accumulation System (ECTS). Students are expected not to fail in the courses. However, YE projects take advantage of non-formal education methods. Participants gather under a roof to carry out specific tasks willingly, without fear of failure and academic worries. The second difference is the duration of the projects. Student exchanges last 3 to 12 months depending on the academic calendar of the hosting institutions. On the other hand, the length of YE projects is 5 to 21 days (European Commission, 2020). The difference in duration between the two programs is a significant difference to be considered and it would be a contribution to the literature to investigate the effects of shorter YE programs. Finally, the distinctive aspect of the present study is the socialization process of the participants. Shvidko (2016) states that foreign language learning is a complex but dynamic process which includes socialization in addition to learners' cognitive development. Student Exchange programs mainly focus on the academic development of the students and students have to cope with the socialization process on their own. On the other hand, YE project and its activities directly focus on socialization. To summarize, YE projects have unique characteristics in comparison to other projects and accordingly, this will be a contribution to the field.

\subsection{Review of the relevant literature}

Until the 1990s, motivation was regarded as a stable learner trait. Dörnyei (2001) summarizes motivation by stating that motivation is responsible for why people decide to do something, how long they are willing to sustain the activity, and how hard they are going to pursue it. Learners who have high levels of motivation try to do their best while learning and they are more active during the learning process. The commonly mentioned constructs regarding motivation for foreign language learning are integrative motivation and instrumental motivation based on the significant work of Gardner (1985). Instrumental motivation results from recognition of the practical advantages of learning, and it is identified when learners say that they want to learn the target language to pass examinations or for economic or social advancement. Integrative motivation is when learners state that they want to learn a foreign language because they are attracted to the target language culture or group or the language itself (Dörnyei, 2001). Intrinsic and extrinsic motivation types are worth mentioning as well. According to Ryan and Deci (2000), intrinsic motivation is the doing of an activity for its inherent satisfactions rather than for some separable 
consequences. It is not only the cause of actions but also an outcome itself (Csikszentmihalyi, 1991). The research of Csizér and Dörnyei (2005) showed that intrinsic motivation is the most influential determinant of motivation. Contrary to intrinsic motivation, extrinsic motivation refers to a set of performance and behavior to attain some other outcome. Extrinsic motivation is the result of any number of outside factors (Harmer, 2007). This type of motivation occurs when the learner utilizes the target language as a tool to achieve the goals he aims. Learners who have such motivation can be highly motivated when the expected reward plays a significantly important role in learners' experience. As opposed to intrinsic motivation, which includes recreation, endurance and psychological comfort (Deci \& Ryan, 2008), extrinsic motivation factors are considered to be favorable when promoting behavioral actions that are not intrinsically motivated. However, Deci (1980) elaborated his original research findings via cognitive evaluation theory and stated that receiver's interpretation of the extrinsic rewards affect the level of extrinsic motivation, which might lead to discount or loss of motivation as the importance of the extrinsic reward might not have the same perception on the receiver as the days pass. In short, motivation is defined as a collection and combination of goal-oriented behaviors. Learners' determination, efforts and desire to reach the set goals determines the level of motivation.

The other significant issue in this study is the speaking skill. Speaking fluency is a significant term in speaking skills and it is one of the most significant goals of language teaching. Speaking fluency is the utilization of the speaking skill effortlessly and in a continuous way to cope with the demands of interaction in a moment by moment fashion. Skehan (2009) promoted the view that fluency can be divided into two aspects, which are speed and repair fluency. Speed fluency deals with the rate and density of the speech while repair fluency deals with the repetitions and corrections. Though different definitions and frameworks can be applied to what exactly fluency is, as the focus of this study is not the conceptualization of fluency, the basic definition by Skehan (2009) will be adopted. It grasps the significance of keeping interaction going and at the same time doing repairs as in natural conversations in real-life.

One final issue to mention is non-formal education. According to the pioneering researchers Coombs and Ahmed (1968), non-formal education is an organized and systematic educational activity. Non-formal education is carried out outside the scheme of a formal system to implement selected types of learning on particular subgroups in the population: adults as well as youngsters and children. As inferred from the definition, NFE can take place in different forms such as sightseeing, weekend activity, holiday and afterschool programs. Non-formal education mainly includes active learning techniques including but not limited to group works, and roleplays, debates (Cooper \& Robinson, 2000; Fuhrman \& Ladewig, 2008). Fuhrman et al. (2005) discovered that participatory approaches to learning, especially cooperative learning activities, helped students improve their attitudes toward the subject matter. 
One of the most crucial parts of NFE is socialization and lack of examination. NFE fosters social interaction among different groups by creating flexible atmosphere. Rather than a teacher-oriented structure of formal education, NFE focuses on the needs of the learner and outputs of the activities. Non-formal education takes place in any situation and area, unlike formal education, where learners are passive and seated in their desks. Learners feel in the middle of the action and education process is not mentioned explicitly. In formal education in Turkey, students are expected to take national exams at the end of secondary and high school and this has a huge impact on their future. They have many exams in schools in the semesters as well. This creates stress and pressure. However, NFE can circumvent this situation to some extent. La Belle (1982) developed the concept of NFE and mentioned that NFE could take part in schools as extra-curricular activities. Later on, Hoppers (2000) divided non-formal education into three different categories: supplementary NFE which is carried out to enrich the activities, compensatory NFE which helps people that have no access to education due to several reasons, and alternative NFE which is an alternative to formal education needs. Accordingly, as a part of NFE, the learning process in YE projects is expected to be improved via the advantages of non-formal education methods (European Commision, 2020).

\subsection{State hypotheses and their correspondence to research design}

As presented above, as a part of non-formal education and out-of-classroom activities, it may be argued that YE projects will have a positive effect on participants' speaking skills and motivation. This study aims to analyze the views of the participants regarding the effect of EU Erasmus+ YE Projects on their speaking fluency and foreign language learning motivation. Hence, the researchers preferred a qualitative research model via a standardized open-ended interview. The research aims to explore the following questions:

1. What are the participants' views regarding the contribution of EU Erasmus+ Youth Exchange Projects to their English speaking skills?

2. What are the participants' views regarding the contribution of EU Erasmus+ Youth Exchange Projects to their English learning motivation?

Via these questions, the effects of the YE programs will be evaluated according to the participants' views and the focus will the effects on speaking skills (i.e. the first research question) and the English learning motivation (i.e. the second research question).

\section{Method}

\subsection{Research design}


This study has a qualitative methodology and it utilizes a semi-structured interview to collect data from the participants who were recruited via purposive sampling. Yıldırım and Şimsek (2008) describes qualitative research as a kind of design which produces findings arrived at via details and in-depth analysis. The main aim of the researchers in using a qualitative research design in this study is to explore the views of the participants regarding the effects of YE programs on their foreign language motivation and speaking skills.

For data analysis, the researchers used Content Analysis which has become closely associated with qualitative research to identify important aspects of the content of the interviews. Krippendorf (2004) defines Content Analysis as the systematic description of the contents in a bottom-up fashion. The aim of the researchers by using Content Analysis was to determine the presence of certain words, concepts, themes, phrases within texts and sets of texts and to evaluate this presence in an objective manner. The researchers follow the steps of Content Analysis method as follows; firstly, the data collected for the research were read in detail. Secondly, units and categories of the analysis and a set of rules for coding were developed and finally, the data were coded according to the rules set by the researchers. Content Analysis provides interpretive analysis by going deeper into the underlying meaning of the data considering the focus of this study.

\subsection{The context and participants}

EU education program is an educational aid program from which member and candidate countries can benefit. Erasmust is a new program area which is being implemented instead of the Life-Long Learning and Youth Programs between 2007 and 2013. Located under the Key Action 1 (KA1) Mobility of Individuals, YE projects provide an opportunity for young groups to carry out projects for up to 21 days. During a YE, the participants carry out the activity program prepared and designed jointly. This develops competences in awareness of socially relevant issues and thematic areas, new lifestyles and traditions primarily through peer education discovery styles. Non-formal education methods are also utilized during the learning process in a YE project. A high foreign language proficiency level is not needed to participate in a YE. People from the age of 13 to 30 can apply for these projects as a delegation of Non-Governmental Organization, organization, public institution, or independent, informal youth group.

As for sampling, according to Dörnyei (2007), the main goal of sampling in qualitative data is to find individuals who can provide rich and varied insights into the phenomenon under investigation so as to maximize what can be learned. Therefore, the distribution of experience in the population and how the respondent sample is represented is not relevant in qualitative research. Initially, the researchers interviewed 13 participants living in Edirne and Sakarya; however, before the analysis of the data, due to a significant range in age and educational background, 3 participants' interviews were excluded to ensure that the group is homogenous as a 
wide range of age and educational background could decrease the reliability of the study. The researchers also ensured that the involved participants had not been involved in any other type of Erasmus+ program except for YE projects.. As a result, the research was conducted with 4 male and 6 female participants who had a university degree and their age range was also made homogenous as mentioned above. As seen in Table 1 below, it varies between 27 and 30 now. As a qualitative study, this study by no means intends to make a generalization. Rather, the goal is to investigate the views and experience of the group in detail in a bottom-up fashion via Content Analysis. In this way, the views and experience of the individual participants will be unearthed.

Table 1. Information about the participants

\begin{tabular}{llll}
\hline Code & Gender & Age & Level of Education \\
\hline P1 & Male & 30 & undergraduate \\
P2 & Female & 29 & undergraduate \\
P3 & Female & 30 & undergraduate \\
P4 & Female & 28 & undergraduate \\
P5 & Male & 28 & undergraduate \\
P6 & Female & 27 & undergraduate \\
P7 & Male & 29 & undergraduate \\
P8 & Female & 27 & undergraduate \\
P9 & Female & 31 & undergraduate \\
P10 & Male & 29 & undergraduate \\
\hline
\end{tabular}

\subsection{Data collection and analysis}

Data for this study come from open-ended structured interviews. Interview questions (Appendix A) have been developed about the YE projects in general, activities in the projects, personal views about the importance of projects on English speaking development and English learning motivation. As a part of receiving expert opinion to increase validity and reliability, the researchers kindly asked for expert opinion from two associate professors in ELT and Testing and Evaluation Department in Trakya University to review the questions in the interview and research questions. The researchers analyzed the interviews in a bottom-up fashion by using MAXQDA 2018 application. MAXQDA is software designed by Verbi GmbH in 1995 and released in 2019 for computer-assisted qualitative and mixed methods research. It allows researchers to collect, transcribe, organize, code, analyze and visualize the data.

The coding process in research involves recognizing a vital moment and encoding it before a process of interpretation (Boyatzis, 1998). The researchers utilized inductive coding method, which allows the theory to emerge from the content of the data. Applying inductive coding, the researchers carefully checked the data and considered multiple observations that were inherent in the documents. The researchers then 
identified text segments that contained meaning units and created a label for each category. Transcripts were also read horizontally to categorize the layers of the texts. As Marshall $(1999,419)$ advises, "coding and categorizing were carried out until no new themes emerged, which suggested that the researchers identified major themes". Accordingly, the data were analyzed in cycles until no new themes were left.

\section{Results}

This study aimed to unearth the views of participants that took part in YE projects. Accordingly, the interviews were analyzed via Content Analysis and the emerging themes were organized until no significant theme was left. In the paragraphs below, the emerging themes will be presented with regard to speaking skills and motivation, which are the research questions of this study.

In Table 2 the results were summarized to give the readers a general idea about the findings. The detailed findings were provided in the following sections.

Table 2. Summary of the Findings

\begin{tabular}{ll}
\hline Codes & F \\
\hline Motivational Increase & 10 \\
Fluency Development & 10 \\
Opportunity to Practice & 5 \\
Comments on Previous Fluency & 6 \\
Negative Comments on Turkish Education System & 4 \\
Educational Equality provided by Erasmus + & \\
Follow-up activities after the projects & 2 \\
& 6 \\
\hline
\end{tabular}

\subsection{Development of speaking skills}

The first research question aims to unearth the participants' views regarding the contribution of Erasmus+ to their speaking skills. All the 10 participants involved in the project clearly stated that they had improved their foreign language speaking skills. For instance, P1 says, "I can frankly say that both projects I participated in have definitely improved my English speaking skills." P5 suggests, "It helped me to relieve the excitement about speaking English, by improving my speaking skills." and P10 also says, "I think that the projects have contributed to my English speaking skills." As seen in these quotes, participants think that the experience helped them improve their speaking skills.

\subsubsection{Fluency development and activities}

The researchers asked further questions to unearth what made participants think that the projects developed their speaking skills. It was found that active learning techniques including but not limited to group works, role plays and debates designed within NFE methods foster communication among participants, and this leads to an opportunity to practice. For instance, P2 says, "I definitely think that I have gained 
fluency." P1 stated that the comfortable and friendly environment in Youth Projects helped him overcome his fear of speaking. P1 defined the friendly climate by saying, "we generally carried out collaborative group works. In these events, there was a creative and comfortable environment where each participant shared his/her knowledge, made common decisions by talking together, and influenced and taught something to one another." P2 states, "There were many people from different countries and English was the only common language that we could communicate through. Since we had to speak English during the activities and spare moments, my speaking performance improved day by day." P2 also states, "Because you live with many foreigners 7/24 hours for eight days. You are together from dusk to dawn. Speaking English on a daily basis becomes inevitable. Since you share many things together, need for and time and ways of communication increase, and so do the opportunities to use English." These findings match the results of Cooper and Robinson (2000) and Fuhrman and Ladewig (2008). Through the activities, good teaching is acquired along with good friendships, as Brian et al. (2009) stated.

\subsection{Motivational development}

The second research question aims to unearth the participants' views regarding the contribution of Erasmus+ to their motivation. All of the 10 participants thought that the experience contributed to their foreign language learning motivation. To exemplify, P3 says "I think all young people should be involved in such projects in order to gain self-confidence in foreign language skills and increase their language learning motivation." P6 also says, "These projects changed my opinion about the importance of English a lot. I realized that I am curious about cultures and languages. My perspective expanded, so my curiosity increased, which triggered my desire to learn more.". Similarly, P4 states, "Imagine that you are in a project with 6 participants from 8 different countries each. You are in an organization with almost 50 people, and each person is unique. You would definitely want to meet such amazing people. You would not like to spend your hours sleeping but talking to people and getting to know them. It is almost impossible to lose your motivation in such a project." P1 also states, "In projects, we generally carried out collaborative group works... Seeing that I could speak to young people from all over Europe more easily than I had thought made me more enthusiastic about the future." P9 also states, "Communicating with people from different countries also motivated me once again to improve my English to use it for leisure activities, such as meeting new people, sharing knowledge and getting to know new cultures etc." P4 underlines the effect of friendship on motivation by saying, "The activities carried out, in the beginning, are called ice breakers. They enable participants to get to know others, learn names, and to create a friendly atmosphere... It is not only the activities but also people around to you that motivate you."

The following results demonstrate how the YE project contributed to increasing their intrinsic motivation. P5 who was afraid of making mistakes figured out with the projects that he needed to practice more to keep his English alive and so he said that 
he had a Europe tour, visited eight countries and in 2019, he visited Thailand. The participant added that although it was not the same as being in a project, he always tried to find some opportunities to practice English and keep it alive. Another interviewee, P7, stated that after this project, with the excitement of seeing a different country and different cultures, he is planning to become a pilot in order to make this excitement permanent. He is working to bring himself to a level of English sufficient for this profession. The participant attended language courses at a private English Language teaching institution as well and took pilot training courses to become a pilot.

The findings demonstrate that the participants benefited from many opportunities of the projects such as travelling abroad, visiting new places, being in a different environment, meeting new people from different cultures, being involved in various activities and tasks, promoting their own culture and country and learning new cultures. These sets of actions trigger the desire to learn, as Baloto (1996) stated. So, considering the findings of this study as well, it can be argued that this situation encourages participants to be involved in the process and motivates them to learn. The results suggest that YE projects make language learners have high levels of motivation, and they try their best to learn English and keep their learning process more active. Their own free will of applying different learning strategies enhance the effectiveness of learning behavior as Dörnyei (2001) suggests. The participants wanted to improve or keep their level of English due to inherent satisfaction rather than for some external consequences. This is intrinsic motivation and according to Harmer (2007), many researchers came to the common conclusion that intrinsic motivation produces a better result than extrinsic motivation does.

\subsubsection{Contribution of the atmosphere of youth exchanges to motivation}

Youth Exchange projects are usually the first opportunity in which most participants have to use their foreign language out of the classroom and this is expected to result in anxiety. However, the findings suggested the opposite. For instance P3 says, "The projects contributed to my speaking skills because I was constantly speaking English 24/7 for ten days. It helped me to overcome the fear of not being able to speak, and I have practiced a lot." As the participant stated, most of the participants had speaking anxiety which could develop due to several reasons. However, thanks to YE activities which are based on friendship, as Brian et al. (2009) stated, participants overcame their anxiety problems. To exemplify, P4 says, "In projects, there are dozens of activities, and these activities let you cooperate with people from other countries, and you are pushed to speak and transfer the knowledge." These views of the participants revealed that the friendship gained during the YE projects provided excessive communication without fear of making mistakes to the participants and they developed their language skills via developing their self-confidence. These findings also support Krashen's affective filter hypothesis. In his theory, Krashen (1988) stated that affective factors include 
motivation, attitude, anxiety and self-confidence. He also argued that people acquire second languages as long as they are exposed to comprehensible input and their affective filter are low enough to allow the input "in".

\section{Discussion}

The primary objective of this study was to unearth the effects and contribution of Erasmus+ Key Action Mobility YE projects on the participants' views on foreign language learning motivation foreign language speaking fluency. The analysis of the qualitative data showed that all $(\mathrm{N}=10)$ participants thought that they either improved their foreign language speaking fluency and that they had a higher foreign language learning motivation. In this section, the results presented in the results section were discussed in light of the studies in the literature.

Key Action 1 mobility of the learners and staff is a commonly well-known action which provides opportunities for higher institution students, professors as well as the staff of educational institutions. Due to being widely-known by academic staff, this action has been in the center of numerous studies. For instance, Kayaoğlu (2016) carried out qualitative research and figured out that the majority of the Erasmus students confirmed that they improved their foreign language skills. The study of Kayaoğlu (2016) also mentioned that students suggested that strictly focusing on form in their previous formal education prevented them from having fluency. The participants of Kayaoğlu's (2016) research argued that they discovered the value of focusing on meaning. The findings of Kayaoğlu's (2016) research are similar to the findings of this research.

Other significant studies such as Özdemir (2019), Gürlek (2019), Mulcar (2019) and Fombana et al. (2013) studied the effects of studying abroad and it was revealed that Erasmus students developed their foreign language proficiency. Even though the present study differs from the studies mentioned above as their target group took formal classes and formal education methods were carried out during their study, both previous studies and the present study revealed that Erasmus projects provide learners social interaction and opportunity to practice. In this sense, both longer Erasmus projects and also YE projects seem to have a positive effect on improving language skills.

The results demonstrated that 4 participants complained about the national education system and blamed it for their failure in foreign language speaking fluency. While meeting different people from different countries and living together for a period of time, participants in the YE projects possibly had the time to talk about various topics including their lifestyles, countries and services provided by the government of their own country. Participants self-evaluated their previous education opportunities, especially English classes and tried to find out the reasons for lacking English proficiency. P1, for instance, claimed that although he graduated from an ELT department, he had a low speaking skill due to reasons such as not being able to practice speaking English during his education. He added that the education system 
at the university had inefficient and inadequate English speaking lessons and lacked English speaking opportunities for communication. Another point that is mentioned by $\mathrm{P} 1$ is the artificiality of the speaking lessons. P1 said that speaking classes and activities carried out in his education system takes places in an artificial atmosphere that neither attracts nor motivates learners to improve or develop foreign language skills. He added that he had never felt the necessity of speaking so much before. P6 also noted that in the first days of the project, she had a bit of timidity due to her education system, but the project reversed it and in fact, brought back self-confidence. P2 similarly mentioned that she realized that she was trained in a perfectionist education system and this was not really necessary. She added that the perfectionist system prevented her from learning and that resulted in unwillingness to learn English. As can be deduced from the results of the interviewees, authenticity in English speaking classes cannot be obtained, and there is an evident problem of overcorrection in the national education system. According to Walsh (2011) and Holley and King (1971), when the focus in on interaction, the instructor should allow the students to complete their contribution without interruption.

Another theme in results was the follow up activities carried out after the projects $(\mathrm{N}=6)$. YE projects contribute much to participants' personal developments and provide international identity to institutions (European Commission, 2020). In line with this, the research has found out that YE projects, while creating an opportunity for their participants to spend a short period in an international atmosphere and practice a foreign language in the meantime, developed intrinsic motivation in the participants. 6 of participants stated that they carried out several activities to keep their learning process alive that is what Ryan and Deci (2000) calls intrinsic motivation and according to Harmer (2007) intrinsic motivation produces better results for learners. This is evidence that YE projects increase motivation and the participants do further activities themselves. The results also suggest that YE projects enabled participants to self-evaluate their foreign language level. The friendship and atmosphere muster intrinsic motivation as well and the participants who felt that they needed to improve their knowledge tried to be involved in other projects to keep the learning process alive. To exemplify, P3 said that she tried to be involved in these activities again. She gathered up her colleagues to write EU projects for the school she worked at, and she added that all young people should be involved in such projects in order to gain self-confidence in foreign language skills and increase their language learning motivation. As seen from this view, she developed intrinsic motivation, and she not only wanted to be part of it but also tried to create opportunities for her colleagues and students. P4 noted his level of English as mediocre but also added that due to lack of vocabulary he was not able to communicate or introduce himself, but even with that level, he said that he still kept chatting with his friends online. The participant watches movies with subtitles, and even when he is free, he tries to have some conversations in his mind by creating a situation. P10 stated that he tried some online applications, such as Skype, to keep in touch with his friends from the project and maintain his level of fluency. The 
participant also watched Netflix movies with subtitles, even sometimes without subtitles, to practice listening and learn the pronunciation of the new words. These comments of P4 and P10 clearly reveals that they have become good learners, fitting into the description of Rubin and Thompson (1982). They are willing to practice as often as possible and try to get a message across even if the specific language knowledge is lacking. In the results about additional activities and increasing motivation, the ambition of P7 and P5 about not being scared of making a grammatical mistake while speaking show that they both acquired intrinsic motivation towards learning English.

Another theme in the findings is educational equality (Table 2). YE projects provide financial support for its participants, and this not only leads to educational equality but also provides the chance to go on an abroad trip for the first time. 2 participants (P1 and P10) stated that they would not travel and meet with so many people when they were university student with a limited budget. Being provided that opportunity and immense excitement about travelling and using foreign language out-of-classroom motivated participants to be more involved and eager to cooperate in the projects. Besides, those mobilities created self-confidence to develop team-work skills of the participants as participants travelled abroad together most of the time, and they needed to act as one group who presented their country.

Another effect of Youth Exchanges on participants is improving the participants' creativity. Many participants are not used to being involved in Non-Formal Education (NFE) activities, which enable social interaction and self-discovery. Unlike formal education, participants are active and seen as discoverers rather than learners. Before and during NFE activities, participants need to evaluate the requirements of the activity. As an individual or a team, multiple intelligence types create a different perspective that results in the creation of various ways to approach the same question or problem. By these methods and activities, participants observed other participants' ways of thinking, evaluated them as well as theirs, which fosters creativity. It can be seen from the present research that Non-Formal Education methods fosters the learning process and improves learners' motivation. As a foreign language lesson, English lessons can follow NFE methods and include integrative activities which aim for practical use of the language rather than seeking to teach the language. This idea of the researchers is supported by La Belle (1982), who developed the concept of NFE and mentioned that NFE could take part in schools as extra-curricular activities. The inclusion of non-formal education is argued to increase the teaching effectiveness (Bean, 1996; Nilson, 2003). Therefore, it may be advised that teachers of English that follow formal curriculum implement NFE activities as much as they can to foster the learning process.

One final implication may be for the E-twinning platform. E-twinning is an online platform for staff (teachers, librarians and so on) working in a school in one of the EU countries involved, to communicate, collaborate, develop projects, share and be part of the learning community in Europe. E-twinning is co-funded by Erasmus+. These online platform projects such as E-twinning are encouraged by the Republic of Turkey 
Ministry of Education as well. However, projects carried out within the E-twinning platform do not often include the cooperation of international students. Students carry out the projects with their school friends and they are not expected to compare the activities in similar projects carried out in other schools. If the E-twinning platform provided international cooperation and collaboration not only with school staff but also with the students, it could be regarded as a more effective program that constructs relationships among global learners as Brian (2009) stated. By involving interaction and friendship, E-twinning can foster the learning process in many aspects in Turkey.

\section{Conclusions}

The goal of this study was to unearth Erasmus+ YE Project and it effects on foreign language learning motivation and foreign language speaking. Utilizing qualitative research method, the study used open-ended structured interviews (see Appendix A) for data collection. The data were analyzed inductively through MAXQDA qualitative data analysis software and following the steps of Content Analysis, the researchers created the codes below to unearth answers to the research questions:

1. Level of Foreign Language

2. Motivational development

3. Fluency development

4. Opportunity to practice

5. Comments on previous fluency

6. Negative comments on Turkish Education System

7. Educational equality provided by Erasmus + projects

8. Follow-up activities carried out after projects

The analysis of the qualitative data showed that all $(\mathrm{N}=10)$ participants thought that they improved their speaking skills and increased their foreign language learning motivation. In line with the previous studies, this study showed that Erasmus+ Exchange programs contributed to participants' language skills. This study contributed to the literature more specifically by analyzing a context which offers nonformal and out-of-classroom experience. All in all, the YE project, in addition to many social and academic contributions, helped the participants improve their foreign language speaking skills and it triggered their motivation to learn foreign languages by setting an authentic atmosphere to practice, aiming to achieve specifics tasks while respecting cultural and social diversity, integrating participants by applying nonformal education methods and promoting social inclusion.

There are several limitations in this study. First of all, the number of the participants in the present research was limited and only qualitative research method was carried out. Even though qualitative research was the most appropriate design considering the purpose of the study, the findings cannot be generalized and further 
research conducted with more participants and backed up by quantitative methods might reveal some generalizations about the population that participated in $\mathrm{YE}$ projects. Secondly, the present study did not take into account some external demographic factors such as age, gender, department and so on. A further study investigating the effects of such factors can achieve a deeper perspective and explanations as such factors can be important determinants of both foreign language learning motivation and proficiency. Last but not least, the current study did not have the opportunity to analyze the views of the participants before they took part in the project. Studies implementing a pre-test post-test design may reveal deeper perspectives into the literature considering longitudinal changes.

\section{The Research and Publication Ethics Statement}

The Ethics Committee/Board approval for this study was obtained from Sakarya University Ethical Committee/Board in 06/05/2020 by No 61923333/050.99/. No ethical considerations were violated in this study.

\section{The Conflict of Interest Statement}

In line with the statement of Committee on Publication Ethics (COPE), we hereby declare that we had no conflicting interests regarding any parties of this study. This was not funded by any institutions.

\section{References}

Boyatzis, R. (1998). Transforming qualitative information: Thematic Analysis and code development. Thousand Oaks, CA: Sage.

Brain, R., Fuhrman, N., \& De Lay, A. (2009). Characterizing "Good" Teaching in Non-formal Settings. NACTA Journal, 53(3), 50-55.

Coombs, P. \& Ahmed, M (1974). Attacking rural poverty: How non-formal education can help. Baltimore: The Johns Hopkins University Press.

Cooper, J. L., \& Robinson, P. (2000). The argument for making large classes seem small. New Directions for Teaching and Learning, 81, 5-16.

Coşkun, A. (2016). Causes of the "I Can Understand English but I Can't Speak" syndrome in Turkey. Journal on English Language Teaching, 6(3) 1-12.

Csikzentmihalyi, M. (1997). Intrinsic motivation and effective teaching: A flow analysis. In J. L. Bess (Ed.). Teaching Well and Liking It: Motivating Faculty to Teach Effectively, (72-89). London: The Johns Hopkins University Press.

Csizér, K., \& Dörnyei, Z. (2005). Language learners' motivational profiles and their motivated learning behaviour. Language Learning, 55(4), 613-659.

Demirel, Ö. (1999). Öğretme sanatı. Ankara: Pegem Yayıncılık.

Deci, E. L. (1980). The psychology of self-determination. Lexington, MA: Heath. 
Deci, E. L., \& Ryan, R. M. (2008). Self-determination Theory: A Macro Theory of human motivation, development, and health. Canadian Psychology/Psychologie Canadienne, 49 (3), 182-185. https://doi.org/10.1037/a0012801

Dörnyei, Z. (2001). New themes and approaches in second language motivation research. USA: Cambridge University Press.

Dörnyei, Z. (2007). Research methods in Applied Linguistics. Oxford University Press.

European Commission. (2020). Erasmus+ programme guide 2020. Retrieved from https://ec.europa.eu/programmes/erasmus-plus/programme-guide/introduction/how-to-readprogramme-guide_en

Fombona, J., Rodriguez, C., Sevillano, A. P. (2013). The Motivational Factor of Erasmus Students at the University. International Education Studies 6(4), 1-9. https://doi:10.5539/ies.v6n4p1

Fuhrman, N. E., Coopenheaver, C. A., \& Duncan, D. W. (2005). A comparison of first-year college student attitudes toward coarse woody debris following review of brochure and participation in cooperative learning activity. NACTA Journal 49(2) 27-35.

Fuhrman, N.E., \& Ladewig, H. (2008). Educational skits performed by college students in large technical writing classes: Can less structured group assignments positively influence the learning experience? Journal of Faculty Development, 22(2), 112-117.

Gardner, R. C. (1985). Social psychology and second language learning: The role of attitudes and motivation. London: Edward Arnold.

Gürlek, A. (2016). The effect of Erasmus Exchange Program on attitudes towards learning English foreign langauge. International Journal of Languages' Education and Teaching, 4(1), 18-32.

Harmer, J. (2007). The Practice of English Language Teaching. Harlow: Pearson Longman Limited.

Haznedar, B. (2010, November). Türkiye’de yabancı dil eğitimi: Reformlar, yönelimler ve ögretmenlerimiz. International Conference on New Trends in Education and Their Implications, Antalya, Turkey. Retrieved from http://www.iconte.org/FileUpload/ks59689/File/166.pdf

Holley, F. M., \& King, J. K. (1971). Imitation and Correction in Foreign Language Learning. Modern Language Journal, 55(8), 494-498.

Hoppers, W. (2000). From the party/state to multi-ethnic democracy: Education and its influence on social cohesion in Europe and Central Asia region. Educational Evaluation and Policy Analysis, 22(2), 173-191.

Işık, A. (2008). Yabancı dil eğitimizdeki yanlışlıklar nereden kaynaklanıyor?. Journal of Language and Linguistic Studies, 4(2), 15-26.

Kayaoğlu, M. N. (2016). Reality of Erasmus through the eyes of students. The Turkish Online Journal of Educational Technology, 10, 24-30.

Kırkgöz, Y. (2008). Globalization and English language policy in Turkey. Educational Policy, 23(5), 663-684.

Koşar, G., \& Bedir, H. (2014). Strategies Based Instruction, A means of improving adult EFL learners' speaking skills. International Journal of Language Academy, 2(3), 12-26.

Krashen, S. D. (1988). Second Language Acquisition and Second Language Learning. PrenticeHall International.

Krippendorff, K. (2004). Content Analysis: An Introduction to Its Methodology (2nd ed.). Thousand Oaks, CA: Sage.

La Belle, T. (1982). Formal, non-formal and informal education: A holistic perspective on life long learning. International Review of Education, 28 (2), 159-175. 
Marshall, M. N. (1999). Improving quality in general practice: A qualitative case study of barriers faced by health authorities. British Medical Journal, 319, 164-167.

Mulcar, V. (2019). The role of Erasmus Plus KA2 Mobilities in learners' intercultural sensitivity and attitudes towards the English language (Master's Thesis). Available from YOK thesis center database.

Özdemir, G. A. (2019). The effect of studying in EFL context on Turkish Erasmus Exchange students' L2 English language proficiency development (Master's Thesis). Available from YOK thesis center database (Thesis No: 598009).

Ryan, R. M., \& Deci, E. L. (2000). Intrinsic and extrinsic motivation: Classic definitions and new directions. Contemporary Educational Psychology, 25(1), 54-67.

Shvidko, E. (2016). Second language socialization in English programs: Two cases. International Association of Research in Foreign Language Education and Applied Linguistics ELT Research Journal, 5 (3), 193-204.

Walsh, S. (2011). Exploring classroom discourse: Language in action. Oxen: Routledge.

Yıldırım, A., \& Şimşek, H. (2008). Sosyal bilimlerde nitel araştırma yöntemleri (7th ed.), Ankara: Seçkin Yay.

Yurtsever Bodur, G., \& Arıkan, A. (2017). Why can't we learn English? : Students' opinions at Akdeniz University. Gaziantep University Journal of Educational Sciences, 1(1), 1-7.

\section{Appendix A. The Interview Questions}

1. If you evaluate your English speaking skills between 1 and 5, how many points would you give? ( $1=$ lowest $5=$ highest)

2. In which year (s) and in which country (s) did you participate in the European Union Youth Exchange program? Which countries were there as participants?

3. How long did the Project last?

4. Do you think the Project has improved or contributed to your English speaking skills? Please explain why.

5. How did the projects you participated in effect your motivation to speak English? Please provide your opinions.

6. Did you have any difficulty in speaking English in the first days of the Project? If yes, what do you think was the reason for this difficulty, was there a lack of vocabulary, grammar knowledge or other factors?

7. Did you think that your foreign language level was insufficient while communicating during the projects? What is the reason that makes you think so? Please give an example.

8. If you compare the first and last days of the projects, do you think you have gained fluency in speaking English? How did you come to this opinion?

9. Have you changed your opinion about the importance of English when you compare before and after the Project? 
10. Is there anything you would like to mention besides the questions addressed to you?

\section{Copyrights}

Copyright for this article is retained by the author(s), with first publication rights granted to the Journal. This is an open-access article distributed under the terms and conditions of the Creative Commons Attribution license (CC BY-NC-ND) (http://creativecommons.org/licenses/by-nc-nd/4.0/). 